\title{
Fuel Leak Detection on Large Transport Airplanes
}

\section{Behbahani-Pour $\mathbf{M J}^{*}$ and Radice G}

Division of Aerospace Sciences, School of Engineering, University of Glasgow, Glasgow G12 8QQ, UK

\begin{abstract}
Fuel leaking from the tanks can be ignited by different sources, with catastrophic consequences for the flight; therefore it is important to detect any fuel leakage before the departure of the aircraft. Currently, there are no fuel leak detection systems installed on commercial aircrafts, to detect fuel tank leakage, while only a small number of more recent aircraft, have a fuel monitoring system, that generates a fuel leak-warning message in cockpit in the case of fuel imbalance between the tanks. The approach proposed in this paper requires the fuel vent ports on the wings to be replaced with fuel vent valves, which can be controlled to be in open or close position. The fuel vent valve will be in close position, when certain conditions are fulfilled (all the related fuel valves closed, pumps not operating, etc.), the fuel tank ullage area is then pressurized to $4 \mathrm{psi}$ and the rate of change of the pressure is measured over a period. Several experiments have been conducted and, the result show that a continuous fuel leak of one liter per minute can be detected. Further experiments show that if the fuel tank is pressurized to higher pressures, a fuel leak can be detected sooner.
\end{abstract}

Keywords: Airplanes; Ignition sources; Pressures

\section{Nomenclature}

$\mathrm{A} / \mathrm{C}=$ Aircraft

ADIRUS $=$ Air Data Inertial Reference Unit

$\mathrm{ASM}=$ Air Separator Module

$\mathrm{CMD}=$ Command

$\mathrm{CTR}=$ Center

Diff. Press. $=$ Differential pressure

$\mathrm{EEC}=$ Engine Electronic Controller

FTPC $=$ Fuel Tank Pressure Controller

FADEC $=$ Full Authority Digital Electronic Control

FWC $=$ Flight Warning Computer

FCMC = Fuel Control Management Computer

LGCIU = Landing Gear Control Interface Unit

$\mathrm{LH}=$ Left Hand

$\mathrm{LP}=$ Low Pressure

$\mathrm{M}=$ Torque Motor

OBIGGS = Onboard Inert Gas Generation System

PS $=$ Pressure Sensor

$\mathrm{P} / \mathrm{B}=$ Pushbutton

Press $=$ Pressure

SNR $=$ Position Sensor

SOV $=$ Shut-Off Valve

$\mathrm{S} / \mathrm{W}=$ Switch

$\mathrm{VLV}=$ Valve

RVDT $=$ Rotary Variable Differential Transformer

$\mathrm{TK}=\mathrm{Tank}$
Temp. SNR = Temperature Sensor

$\mathrm{XFR}=$ Transfer

\section{Introduction}

There have been several incidents of fuel tank explosion on commercial transport airplanes, which in some cases, have resulted in loss of lives and aircraft. Experts predict that fuel tank explosions on commercial airplanes could escalate due to increased number of electrically operated components inside fuel tanks, such as booster pumps, quantity probes, level sensors, fuel valves, etc. The U.S Federal Aviation Administration (FAA) states that in order to reduce the risk of fuel tank explosion on large transport aircrafts, any internal or external ignition source inside fuel tanks must be eliminated. When heat or a spark of sufficient energy comes into contact with fuel and oxygen, the result will be fire or explosion. Fuel leakage onto hot surfaces such as engine, APU, brakes, wheels, electrical fuel pump, hydraulic pumps, etc., may also result into fire and consequently fuel tank explosion.

The aim of this paper is to present a technique, which can be used on large transport airplanes, to detect fuel leak in fuel tanks before aircraft departure. Fuel leaks could lead to fuel tank explosion, and consequently could result in loss of aircraft and lives. Clearly, it is very important for any fuel tank leakage to be identified and repaired before takeoff. In August 2007, a China Airlines Boeing 737-800, registered B18616, took off from Taiwan International Airport scheduled Flight 120 at 08:23, and landed at Naha Airport at 10:27. It was destroyed by fire, after a fuel tank explosion due to fuel leak [1]. The purpose of minimizing fuel leak is clearly to increase flight safety, by reducing

*Corresponding author: Behbahani-pour MJ, Division of Aerospace Sciences, School of Engineering, University of Glasgow, Glasgow G12 8QQ, UK, Tel: 0096550411737; E-mail: behbaa@yahoo.co.uk

Received September 21, 2016; Accepted October 26, 2016; Published October 31,2016

Citation: Behbahani-Pour MJ, Radice G (2016) Fuel Leak Detection on Large Transport Airplanes. J Aeronaut Aerospace Eng 5: 174. doi: 10.4172/21689792.1000174

Copyright: ( 2016 Behbahani-Pour MJ, et al. This is an open-access article distributed under the terms of the Creative Commons Attribution License, which permits unrestricted use, distribution, and reproduction in any medium, provided the original author and source are credited. 
the possibility of fuel tank explosions but it also avoids a reduction in aircraft range and prevents flight cancellations [2]. Fuel tanks may leak due to several reasons: excessive flexing of the tank structure causing cracking and overstraining of the sealant; sealant ageing; accidental damage; incorrectly set rivets during initial manufacture and more [3]. Additionally, there are several fuel booster pumps and fuel valves, located inside the fuel tanks, and therefore incorrect fuel component installation or defective seals can result into fuel leakage, and possible risk of fuel tank explosions. Fuel valves and pipelines are designed to be $100 \%$ leak proof, however loose joints or damaged seals may nevertheless lead to leaks from such pipes. For safety reason nitrogen is used to pressurize the fuel tanks and fuel system, however ambient air can be used to perform leak check on water/pneumatic/hydraulic/ oil pipelines and associated systems, using the proposed technique. In the proposed technique, in addition it can detect leak in the water / oil / air / hydraulic pipelines, leak proof valves and components.

The methodology presented in this paper, requires pressurizing the fuel tank with nitrogen, and measuring the rate of change of pressure over a period. Nitrogen is used because it is an inert gas, and thus reduces the risk of fire ignition and hence fuel tank explosion. In all aircraft, the fuel tanks are vented into the atmosphere, but in the proposed approach, the fuel vent ports must be closed. Therefore, the fuel vent ports on the wings are replaced with fuel solenoid or torque motor operated fuel vent valves, which can be commanded to open or close position, depending on the operational requirements. To carry out a fuel leak detection test, the tank is then pressurized to 4 psi. Higher pressure would allow a leak to be detected sooner however, this may not be always possible as in some large transport airplanes, such as the Airbus A340-300 series, and there are several carbon disks, which act as overpressure protectors. The overpressure protector installed in the surge tank, breaks to relieve excessive pressure inside the fuel tank. Overpressure protectors are also installed in the fuel pipe between the center fuel tank and the inner fuel tank, and are designed to break between 5-7 psi [4]. Some fuel tanks such as the additional center fuel tank (bladder type) used on the Airbus A320s to increase the range of aircraft, have no over pressure protector, and hence these fuel tanks can sustain higher pressurization values.

Several experiments have been conducted by designing two sample fuel tanks from steel, installed with the pressure gauge to measure fuel tank ullage pressure, fuel pipelines, fuel flow-meter, fuel vent valves, fuel leak valve, fuel inlet and outlet valves, etc. and a flow-meter was used to measure the rate of fuel leak. During the experiment, the fuel tank is pressurized with nitrogen at different pressures, and then a fuel leak at different flow rates is produced, and the pressure drop of the ullage of the tank is measured. The result of the experiment was that firstly, if the size of fuel is increased, then the system detected the fuel leak quicker. Secondly, if the fuel tank is pressurized to higher pressure, then the system can detect a fuel leak in less time. The same technique could be used to detect leakage in air /water /oil /hydraulic pipelines, airtight fuel and pneumatic valves. In most aircraft, very hot, engine bleed air, is used to deice the wing leading edges (slats) and this air is routed via pneumatic ducts to the slats. Any hot bleed air leakage could result into a loss of engine thrust and in order to compensate, the fuel controller increases the fuel flow to the engine, resulting in higher operational costs. Therefore, it is important, to also perform a leak check on the pneumatic ducts before aircraft departure. In such case, ambient air instead of nitrogen can be used. The fuel leak detection test must be performed while the aircraft is on the ground so that in case of fuel leakage, the system can generate appropriate warnings in the cockpit and corrective maintenance action can be taken before take-off.
Following the TWA flight 800 crash in 1996, the US National Transportation Safety Board (NSTB) attributed the accident to the explosion of the center fuel tank. This accident led to the introduction of new regulations by the Federal Airworthiness Authority (FAA) to reduce ignition sources inside fuel tank. Currently, most modern aircrafts have center fuel tank inert system, which uses nitrogen generated by Air Separator Module (ASM) [5]. To perform a leak check on the fuel tanks, the current system can be modified by installation of an air compressor that supplies pressurized, ambient air to ASM when the engine is not operating, and to install fuel vent valves on fuel vent ports in order to isolate the fuel tank from the atmosphere. Therefore, the proposed design can be implemented at little cost, while greatly increasing flight safety.

\section{Accidents Due to Fuel Leak}

It is very difficult for a pilot to determine if there is a leak in the fuel tanks. For example, it was a passenger who saved the lives of 300 passengers, on a flight from Chicago to Tokyo. He spotted an outflow from the wing tip and when the captain was informed he confirmed the leak, and diverted the flight to San Francisco [6]. There have been several other narrow escapes, such as the case of the Japan Airlines flight from Boston to Tokyo on January 8, 2013, a Boeing 787 Dreamliner experienced a heavy fuel leak from left wing fuel tank before departure [7]. On the Air Canada flight ACA216 on November 6, 2003, the pilots did not receive any abnormal engine indications or any other warning, but following indications from air traffic control, they shut down the engine and made an emergency landing; the investigation revealed that the LP inlet fuel line to the fuel/oil heat exchanger on engine 2 was detached thus resulting in fuel leakage. If the pilot had not been informed by the tower, there could have been an explosion or fire [8]. Air Transat, Flight 236 was flying over the Atlantic Ocean on August 24, 2001, when the pilot received a fuel imbalance message but assumed it was a false warning. The pilots followed the standard procedures, and opened the fuel cross-feed valve and switched OFF the right wing pumps in order to feed the right engine from the left wing fuel tanks. However, due to a three inches crack on the fuel tube, a leakage developed on the engine and consequently both engines flamed out during flight, leading to an emergency landing. The leak was due to a maintenance error however, the pilot also made a mistake in assuming a false fuel imbalance warning. After the incident, the investigation recommended that the flight manual be amended, to ensure that fuel is not transferred by opening the cross-feed valve if there is suspicion of a possible leak [9].

Fuel leaks can however lead to disastrous consequences as happened to the China Airlines, B737-800 destroyed by fire at Naha airport in Japan on August 20, 2007, after a fuel tank explosion due to fuel leakage caused by a bolt piercing the wing $[1,10]$ as shown in Figure 1 . The leakage had started shortly after the landing, when the slats were fully retracted inside the wing, as shown in Figure 1, and within five minutes, approximately 60 pounds of fuel leaked from the right main tank and got in contact with hot engine surfaces resulting in fuel tank explosion and the aircraft being engulfed in flames $[1,11]$.

British Airways Boeing 777-236 departed London Heathrow enroute to Harare in Zimbabwe, on 10 June 2004. Immediately after takeoff, a fuel leak was detected and emergency landing initiated. The UK Air Accident Investigation Branch (AAIB) revealed that the fuel leak was caused by fuel escaping through the center fuel tank purge door inside the left main landing gear, shown in Figure 2. The aircraft had recently undergone a scheduled, major maintenance check, during which the center fuel tank purge door was removed for maintenance, 


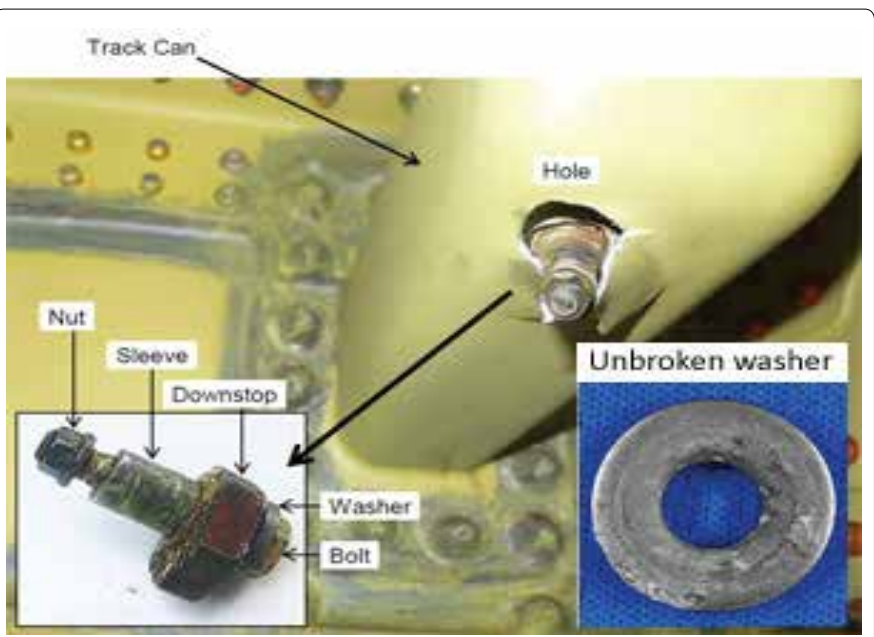

Figure 1: Slat No.5 assembly failed during operation [1,11].
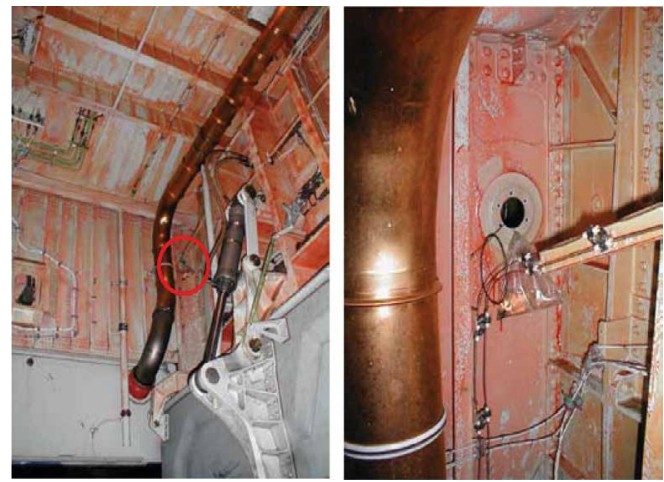

Figure 2: Center fuel tank purge door circled in red was left open by maintenance personnel [12].

but not re-installed after the completion of the task [12]. The most modern airplane Boeing 787 Dream Liner suffered fuel leak on runway, and the passenger alerted the cabin crew. The incident was captured on a video available on You Tube [13].

A UK military accident investigation concluded that the fatal accident of Royal Air Force BAe Nimrod crash on the 2 September 2006, in Kandahar, Afghanistan, which resulted in the death of 14 servicemen, was caused by fractured fuel pipes. As the aircraft was being refueled in mid-air, the leaking fuel from fractured fuel pipe caught fire, possibly due to a spark from faulty wiring [14-17].

\section{Current Operational Fuel Leak Procedures}

Currently, there is no onboard system that can detect a fuel leak from the tanks. The Airbus A320 Flight Crew Operation Manual (FCOM) states that "a fuel leak may be evidenced by either passenger observation (fuel spray from engine or wing tip) or total fuel quantity decreasing at an abnormal rate or if there is a fuel unbalance" [15]. Hence in case of fuel leak, the pilot must land as soon as possible. Operational procedures state that a fuel imbalance between left and right wing fuel tank, greater than $500 \mathrm{KG}$, indicates a fuel leak. This approach however, is of somewhat limited effectiveness, because, fuel imbalance between the two tanks can occur due to many factors: defective fuel quantity probe harness, contaminated fuel probes, leaks from fuel booster pump check valves; unbalanced fuel flow from fuel booster pump; fuel cross-feed valve or fuel inlet valve left in open position; broken fuel delivery pipes, etc.

Several methods are used during aircraft maintenance checks to perform leak test on the fuel tank. A common approach is to totally defuel the tanks, and then manually applying special materials to the internal surfaces of the fuel tank. Compressed air is then applied to the outside of the tank where a leak may be suspected [4]. The disadvantage of this method is that it requires maintenance personnel to enter inside the fuel tanks, increasing the risk of fuel tank explosion if safety advices are not strictly observed. To enter a fuel tank, the fuel tank must be totally dry so it has to be purged with dry air for at least 16 hours, all tools must be free from static charge to avoid sparks, safety shoes to be used, etc., before compressed air is applied to suspected areas. However, if the fuel leak location is not known, then this process is very time consuming. In some cases, such as the fuel trim tank inside horizontal stabilizer there is no space for personnel to access the inside of the tanks.

Other leak detection methods include defueling the aircraft, sealing off the fuel vent ports by installing NACA vent dummy door to the fuel vent ports and then using a manometer, to create a negative pressure of not more than 2.9 psi (to prevent operation of overpressure burst disks). Negative pressure is applied via the dummy door to fuel tanks and then applying a dye solution to the external surface of the fuel allows the identification of the location of leak [4]. The disadvantages of this method are that it again requires personnel to enter fuel tanks, as well as being time consuming. In addition, it requires specialized equipment, and qualified staff to perform the leak test.

Fuel leak test on the additional center, flexible bladder type tank, on Airbus A319/320 requires the tank vent port, fuel drain pipe and fuel transfer pipes must be sealed off in order to prevent air to vent outside the tank during the test. The fuel tank is the pressurized with dry air up to 20.3 psi to detect any leaks [16]. The disadvantage of this procedure is that again it requires special equipment and certified staff.

\section{Fuel Tank Leak Detection System}

In order to perform a fuel leak test, nitrogen in the atmosphere is extracted through an Air Separator Module (ASM) and, injected into the appropriate fuel tank. The pressure level inside the tank is then monitored to ascertain the presence of any leaks. In order to prevent nitrogen escaping through the fuel vent ports on the wings, the fuel tank must be isolated from any vent system as shown in Figure 3. The Fuel Tank Pressure Controller (FTPC) will control the fuel leak detection process, and contain the logic software instructions. It receives position feedback from the valves, fuel pressure sensors, etc., and performs the leak test and displays the result in the cockpit for the flight crew or aircraft maintenance engineers.

In the proposed approach, the fuel tanks are pressurized with nitrogen, and each fuel tank has a fuel vent valve, which closes during the test. The system is able to determine which fuel tank is leaking and leading to corrective actions by maintenance personnel. Location of the leak can be then determined either through visual observation or by applying a soap solution to exterior surface of the tank. The main benefits of this approach are that it does not require specialized equipment or qualified personnel and can be performed at the terminal with fuel inside the tanks.

The FTPC is a controller, which stores the program in its main memory module and determines what actions are required. On large transport airplanes such as Airbus A330/A340 series, the fuel is stored in 


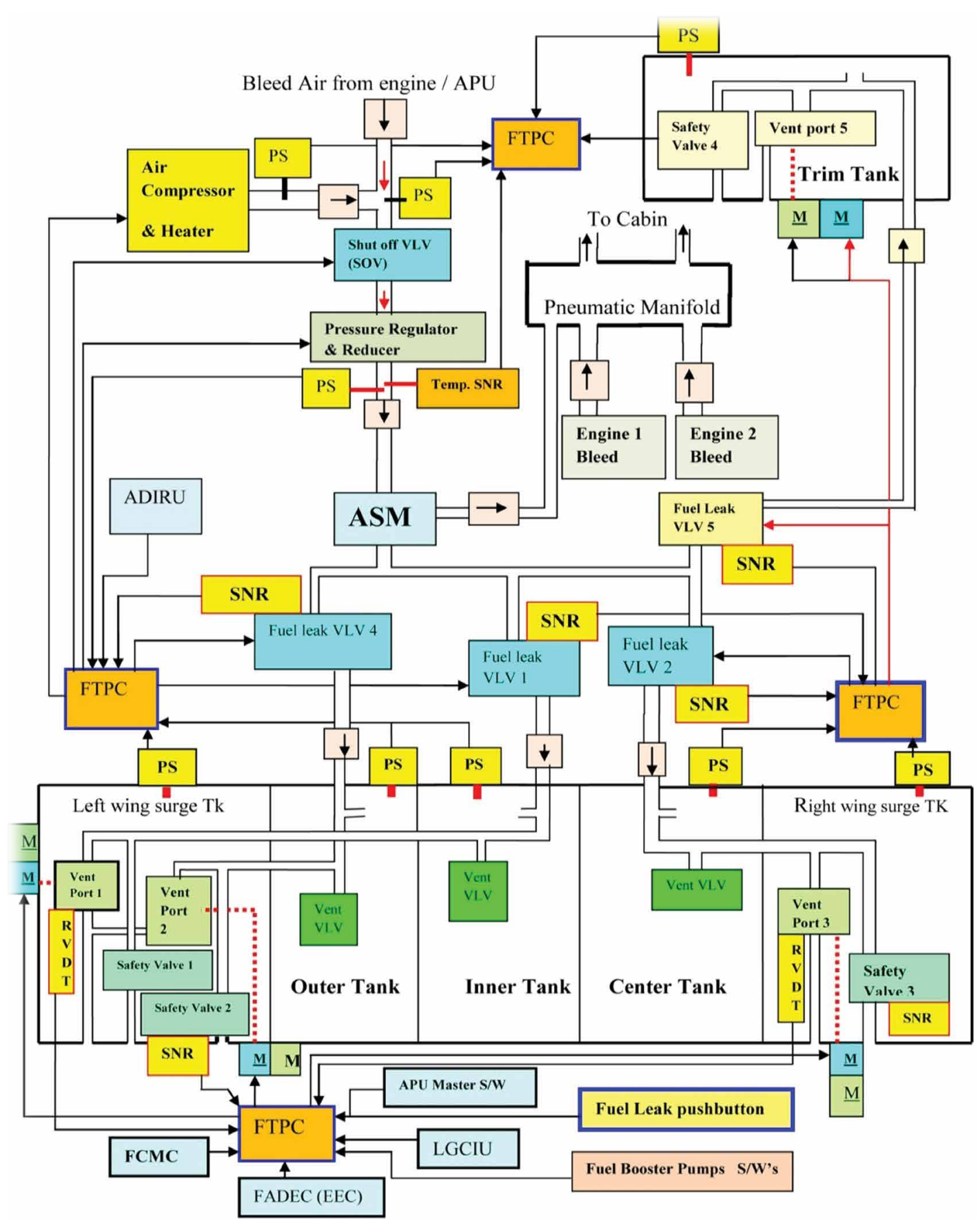

Figure 3: Fuel leak detection system for outer inner and centre fuel tanks on wing.

the left and right wings, centre tank in the forward cargo compartment, and possibly additional centre tanks in the aft cargo compartment, and horizontal stabilizer. Fuel tank in horizontal stabilizer is called trim tank. The wing tanks are divided into inner fuel tanks, and outer fuel tank located towards the wing tip. In the Airbus fleet, fuel is transferred from the centre tank to the inner tanks in the wings so that fuel is left in the wing tanks as long as possible, to avoid excessive wing bending during flight. Additionally, fuel is transferred forward or aft during flight in order to control the position of the centre of mass.

Currently, all transport airplanes have one fuel vent port in the left wing and one fuel vent port in the right wing, and one in the trim fuel tank (horizontal stabilizer). The fuel vent ports in both wings are interconnected to each other so that all wing fuel tanks are linked together, and are permanently open to the atmosphere. However, in the proposed method, each fuel tank has its own fuel vent (valve) port, which is controlled by the FTPC. The reasons behind each fuel tank having its own fuel vent port, are to prevent nitrogen escaping into the atmosphere during fuel tank pressurization, and to easily determine which fuel tank may be leaking. We have used the Airbus A330 fuel system for the proposed leak detection design but believe that it can easily be applied to any other aircraft fuel system. In the proposed 
Citation: Behbahani-Pour MJ, Radice G (2016) Fuel Leak Detection on Large Transport Airplanes. J Aeronaut Aerospace Eng 5: 174. doi: 10.4172/2168-9792.1000174

methodology, the FTPC can be programmed to give the operator the choice to select on which fuel tank the test is to be performed. The fuel leak detection test can be done on individual tanks or all tanks at the same time, regardless of their location or type. The fuel leak test is performed while the aircraft is on ground, and the personnel have to press and hold fuel leak test switch for seven seconds, this is to prevent inadvertent operation of the leak detection system, as part of safety feature, to allow the crew to de-select the system, in case it was incorrectly selected.

Fuel leak test starts when certain conditions are met :all the related fuel valves closed, no fuel transfer, no refuelling / no defueling, no jettison, and fuel booster pumps not operating, etc. as shown in Figure 4. Additionally, the fuel tank should not be full to its maximum capacity, because, if the fuel tank is filled with fuel to maximum, then there is no or very little ullage area in the tank. With the aircraft on ground and engines and APU not operating, there will be no bleed air supply, therefore, the air compressor combined with electrical heater, extracts air from atmospheric, pressurizing it to above $40 \mathrm{psi}$ and heating it. The air supply to ASM is heated to $180 \mathrm{~F}$ plus or minus $10 \mathrm{~F}$, in order to increase the efficiency of ASM then air is supplied to the Air Separator Module (ASM) via the shut-off valve. The ASM supplies nitrogen to the fuel tanks via fuel leak valves, as shown in Figure 3, until the nitrogen pressure reaches the appropriate threshold of 4 psi. Each fuel tank is equipped with two high fuel level sensors located on the top of the tank; and two low fuel level sensors located at the bottom of the tank, in such case, as part of fuel leak test condition, the high fuel level sensors should not sense wet state condition which is maximum fuel quantity. Each fuel tank has its own separate fuel vent port controlled by FTPC, this is done in order to identify which fuel tank on aircraft is leaking fuel (failed the test), so to assist the engineer in trouble shooting while reducing time and manpower.

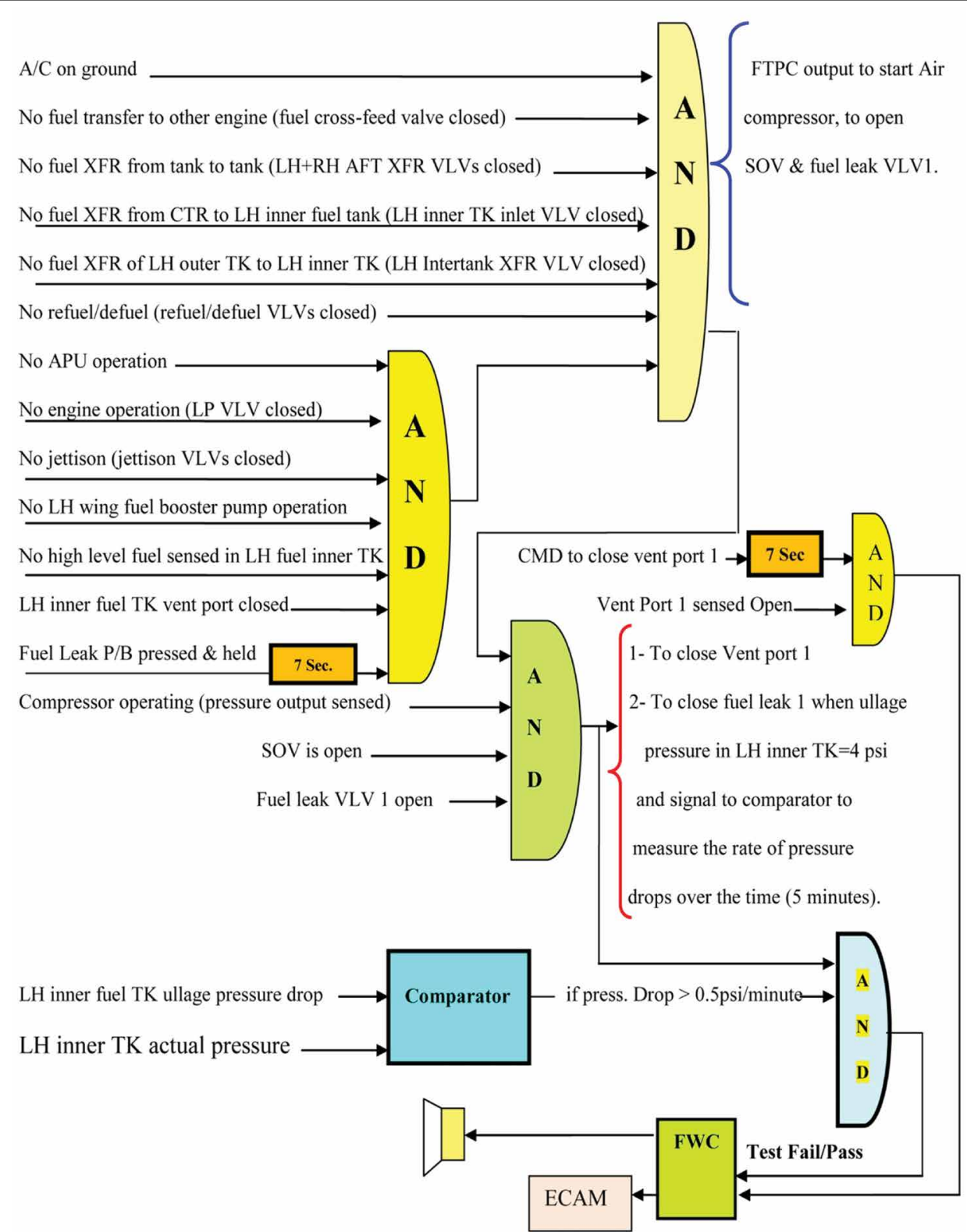

Figure 4: FTPC fuel leak detection in left inner fuel tank. 
The FTPC receives the fuel tank ullage pressure data and measures the rate of change of pressure. With the fuel tanks pressurized to 4 psi if there is no pressure drop after five minutes then fuel leak test is satisfactory and a text message appear in the cockpit for crew attention and they can switch off the leak test system. However, if the leak test is not satisfactory, the FTPC will send signal to Flight Warning Computer (FWC) to generate oral and text warning messages on ECAM screens and the maintenance personnel have to take corrective action to rectify the defect before the aircraft departure. In order to perform a fuel leak test on the centre fuel tank, then certain conditions must be fulfilled, as shown in Figure 5.

\section{Safety Feature}

In case of the proposed system design malfunctions, such as over pressurization of the fuel tank during fuel leak test, the FTPC will command the shut-off valve to close, to stop the tank pressurization, in order to prevent damage to the wing structure. In case of excessive differential pressure, the safety valve installed in the surge tank opens. In the proposed approach, there is one safety valve, which connects all the wings tanks to the atmosphere as well as one safety valve for the trim tank. The FTPC has an ambient pressure transducer to determine the ambient atmospheric pressure, while as a back-up the FTPC receives ambient pressure data from air data computers known as Air Data Inertial Reference Unit (ADIRU). The FTPC, compares the internal pressure of the fuel tank with ambient atmospheric pressure and if the maximum differential pressure between the tank ullage pressure and ambient air pressure exceeds the aircraft manufacturer structural limit, then FTPC will command shut-off valve (SOV) to close, and hence stop fuel tank leak test. A fuel tank can withstand certain amount of mechanical stress, without any failure, due to the differential pressure between the fuel tank and ambient air pressure. However, modern aircrafts such as Boeing 787 Dreamliner using composite materials can tolerate much higher structural stress than metal fuel tanks, due to higher flexibility higher resistance to mechanical fatigue [18].

In addition, for safety reasons, the fuel vent valve is controlled by two torque motors, so that in case of one torque motor fails, the second will take over. In case, the fuel vent port valve fail in close position, the position sensor senses the position of the valve, and the controller compares the command output with actual valve position, thus generate warning in the cockpit. The fuel vent port valve can be moved to open position manually, in order to dispatch aircraft on time. In addition, the fuel vent valve can be a solenoid-operated valve, with two coils, which can move the fuel vent port to fully open or close position. The position sensors or RVDT provides position feedback to FTPC.

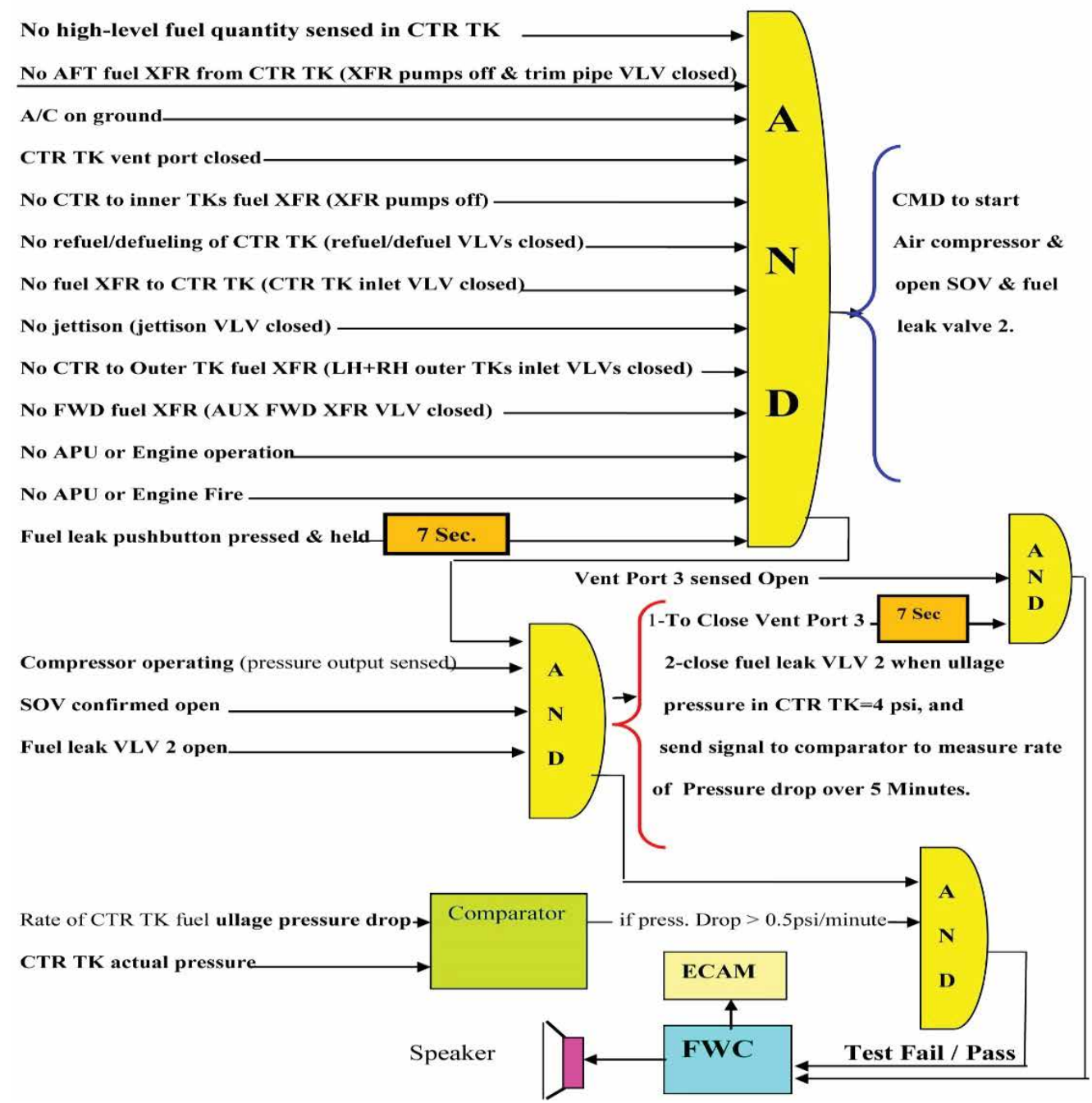

Figure 5: Fuel leak detection conditions for center tank. 


\section{Safety Valve}

The safety valve design, shown in Figure 6, consists of a diaphragm held by spring tension, and in case of positive differential pressure of more than XXXX psi, the valve moves down (opens) and allows the fuel tank to vent into the atmosphere. The safety valve proximity sensor-2 will sense the proximity of the valve and send a signal to FTPC to indicate that there is a positive maximum differential pressure, and the FTPC will command shut-off valve (SOV) and to stop the pressurization of the tank. In case of negative differential pressure (atmospheric pressure greater than fuel tank pressure), the safety valve moves upward (opens) and allows air to enter the fuel tank. As the valve moves upward, the safety valve proximity sensor- 1 will sense it, send signal to FTPC, which in turn, will command the pressure regulator to open more, to increase air supply to the ASMs in order to supply more nitrogen flow to the fuel tank, and reduce the differential pressure to be within the limit.

\section{Fuel Tank Leak Detection Experiments}

The hypothesis that underpins this work is that if a vessel is leak proof, then when pressurized with air or nitrogen, it should not experience any pressure drop. During the experiment, the ambient pressure of day was $1013 \mathrm{mb}$ and ambient temperature of $30^{\circ} \mathrm{C}$.

Figures 7-9, present the experimental setup used to validate the fuel leak detection system. Two galvanized steel tanks with a capacity of 62 liters are equipped with several ports for pipeline connections. All pipelines had washer seals and sealant applied to all joints to ensure that the tank is air-tight. A flow-meter is screwed on the pipelines, and there are also several shut-off valves (SOV). All valves are opened and closed manually during the experiment. A Bourdon tube type pressure gauge is screwed on the top of the tanks, to measure the tank ullage pressure. Initially, SOV 2 and SOV 3 are fully closed, and the vent valve 1 opened fully, to allow trapped air to escape while 27 liters of fuel are transferred to fuel tank\#1 through SOV 1. When the fuel has been transferred vent valve 1 is closed manually. Dry nitrogen stored under high pressure is then connected to the inlet of SOV 1 through a flexible hose. SOV 5 is opened very slowly, to allow nitrogen to flow into the tank to a pressure of 2 psi. The fuel leak simulation valve is then opened to simulate fuel leak of half of liter per minute, as shown on the flowmeter with the leaking fuel being collected in a container. During the fuel leak experiment, the pressure gauge was monitored to assess any pressure changes. At the same time, when the fuel leak was simulated, a timer was used to determine when the pressure on the gauge started to change.

As shown, in the Figure 10, it takes just over three minutes for the pressure to change. Different fuel leak flow rates were generated, by varying the opening of SOV. With a fuel flow leak rate of 1 liter per minute it takes just over two minutes before the pressure gauge registers a change in ullage pressure. Clearly as the fuel leak rate is increased, any pressure change is detected more rapidly. A further experiment, in which the fuel tank $\# 1$ is subjected to pressures above $4 \mathrm{psi}$, is conducted. The purpose of this experiment is to determine the effect of pressurization on leak detection time. Therefore, tank \#1 pressurized to 6 psi, then with all the valves closed, SOV 3 , fuel-cross feed valve, fuel tank vent 2 is opened manually and fuel is transferred from fuel tank \# 1 via SOV 3, flow-meter, and fuel-cross feed valve to fuel tank \#2. It was observed that if fuel is transferred from one tank to another, it affects the pressure of fuel tank ullage area; therefore, it is important that during fuel leak test, there should be no fuel transfer between the fuel tanks. Therefore, this condition is reflected in the proposed approach, as part of requirement logics, that there should be no fuel transfer, no defueling and no refueling of the fuel tank during the leak test.

With all the valves closed, the nitrogen bottle pressure regulator is manually adjusted to read 4 psi and SOV 1 opened slowly to allow nitrogen to pressurize fuel tank \# 1 . SOV 1 closed when the pressure gauge showed 4 psi. Then SOV 3 is opened to let fuel to inlet of the flow-meter, and the fuel leak simulation valve is slowly opened to create a fuel leak of one liter per minute. It was noted, as shown in Figure 11, that it takes around 1 minute for a pressure change to be observed on the pressure gauge. This experiment was then repeated by increasing the ullage pressure by 2 psi. It can be seen that an increase of 2 psi results in a decrease of approximately 10 seconds in the time to detect a fuel leak.

During the experiment, the ambient pressure of day was $1013 \mathrm{mb}$ and ambient temperature of $30^{\circ} \mathrm{C}$.

Analysis and conclusion of the experiments show that higher

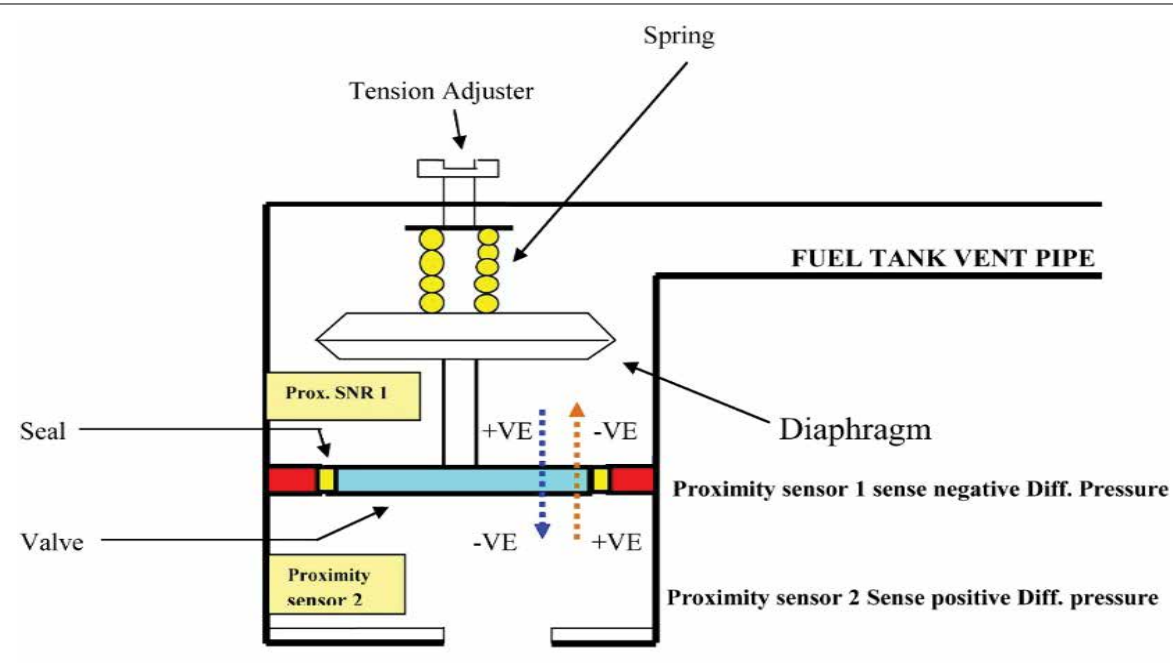

Fuel Tank Safety Valve

Figure 6: Fuel tank safety valve. 


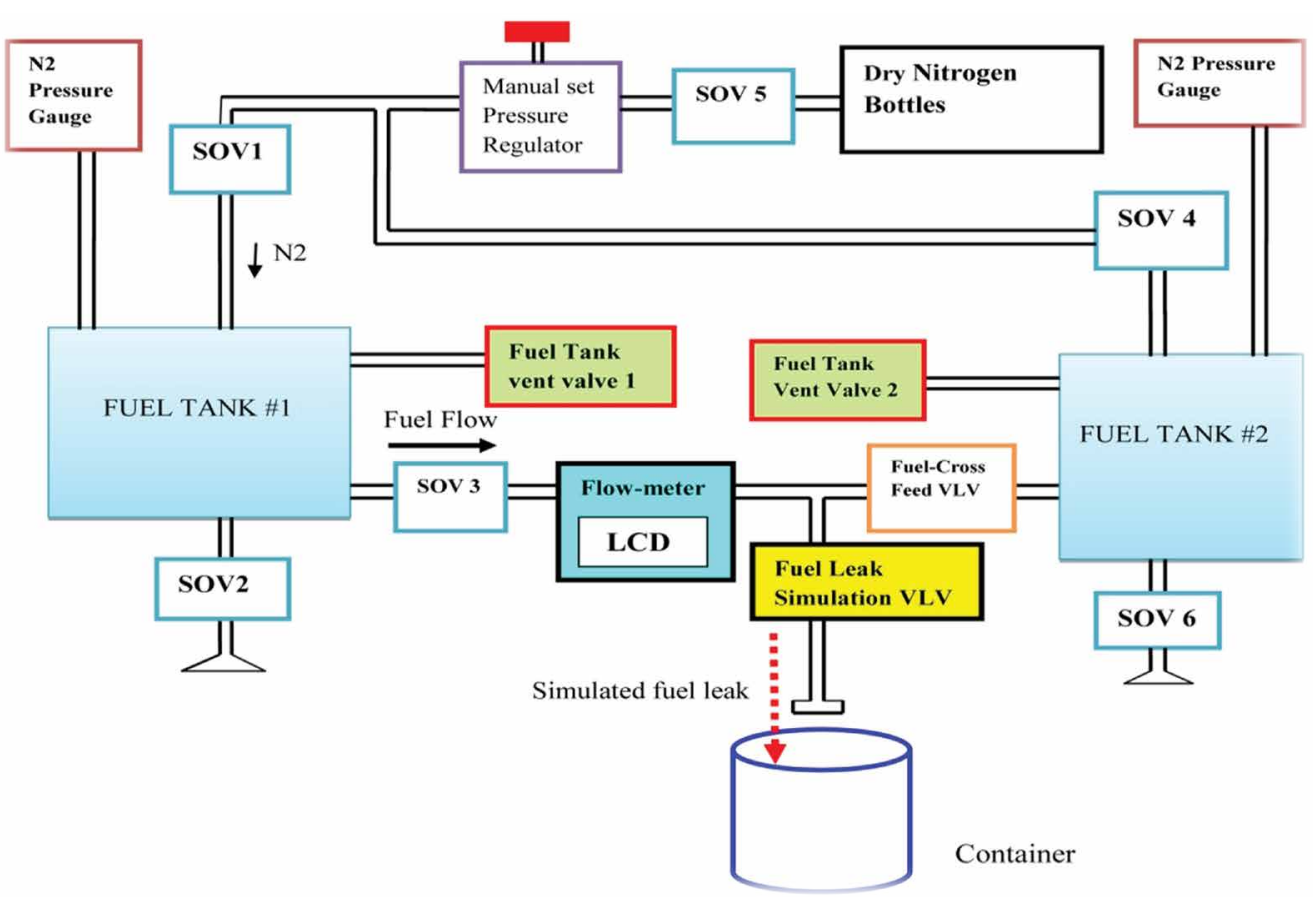

Figure 7: Fuel leak detection experimental setup.

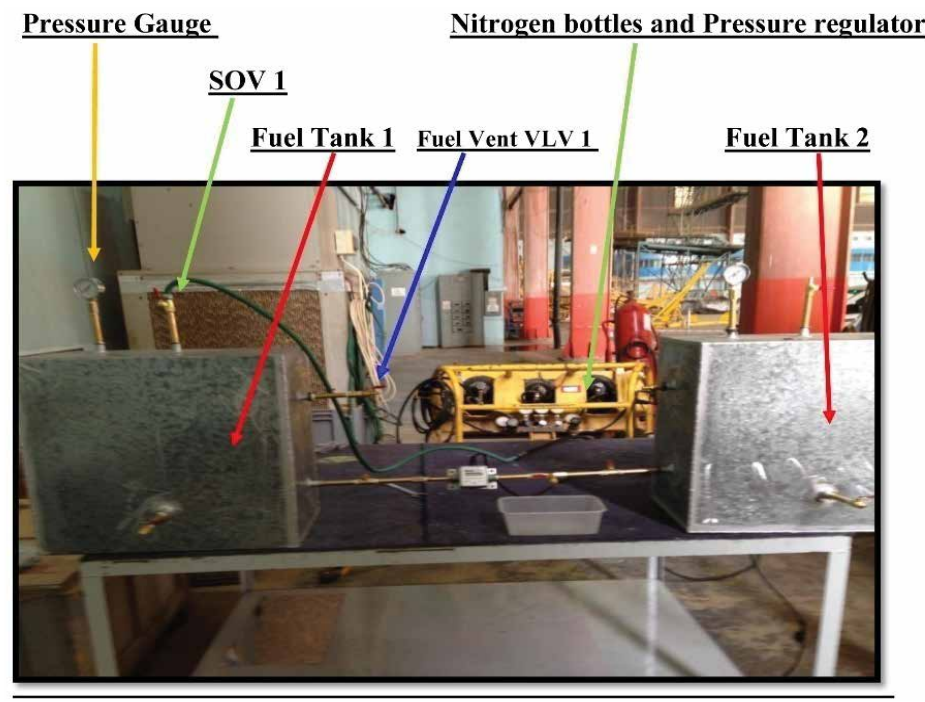

Figure 8: Fuel leak detection experiment and components

pressures lead to quicker leak detection, additionally if the leak is increased, then it is identified sooner. The reason behind this is that when the tank is pressurized to higher values, a small leak causes a large drop in tank ullage area, and at a faster rate, thus result in quicker leak detection time. Because by increasing the nitrogen pressure, it increases the head pressure acting on the fuel quantity, and hence a small opining as in case of tank leakage, allows the fuel to spill at higher flow rate, and ullage area to increase at faster rate. Analysis of the experiment also showed that during testing there should be no fuel transfer or defueling/refuelling, as this will result in changes in the ullage pressure and hence could lead to inaccurate or misleading results.

The proposed approach presents many advantages when compared to current fuel leak detection approaches. It can quickly determine if and which fuel tank is leaking, thus reducing trouble shooting time and manpower, and possible flight delays. It does not require the aircraft to enter the hangar, as the fuel leak test can be performed while the aircraft is at the terminal. Currently, if there is a fuel leak, the tanks have to be defueled, and purged with dry air to get rid of fuel vapours; however, the proposed approach does not require all this. If the test detects a pressure change, evidence of a possible fuel leak, then by applying soap solution to the external surfaces of the tank, the exact location of the leak can be identified through bubble formation. Finally, the proposed approach does not require maintenance personnel to enter fuel increasing workplace safety. 


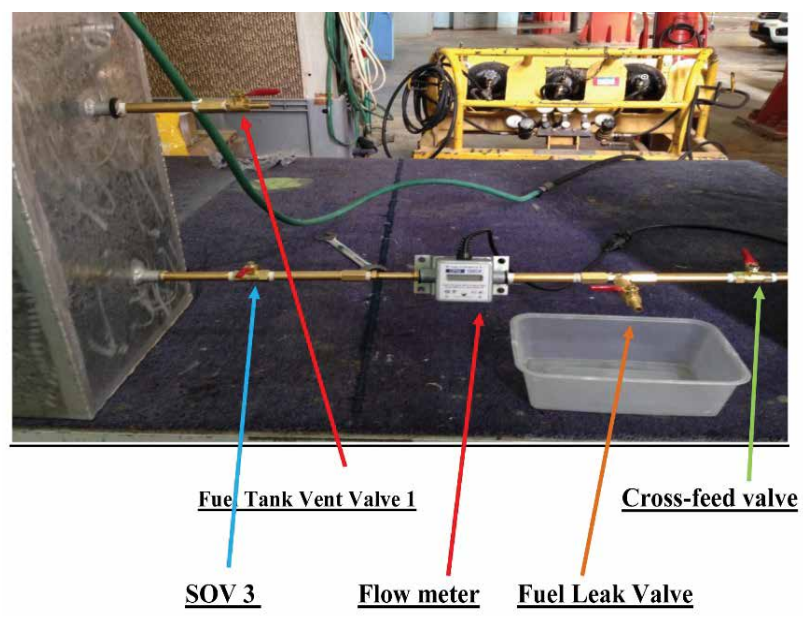

Figure 9: Fuel leak detection experiment.

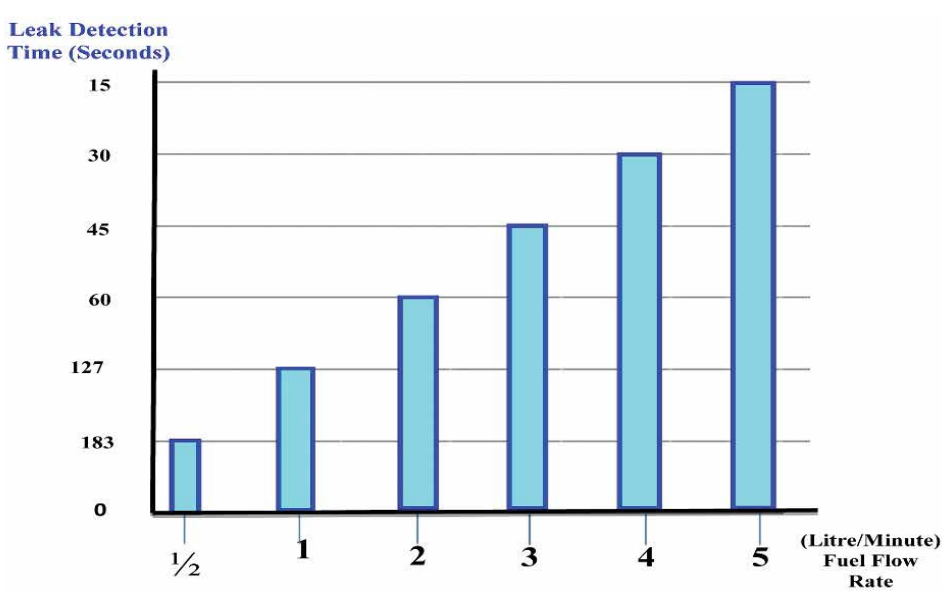

Figure 10: Leak detection time as a function of leakage flow rate.

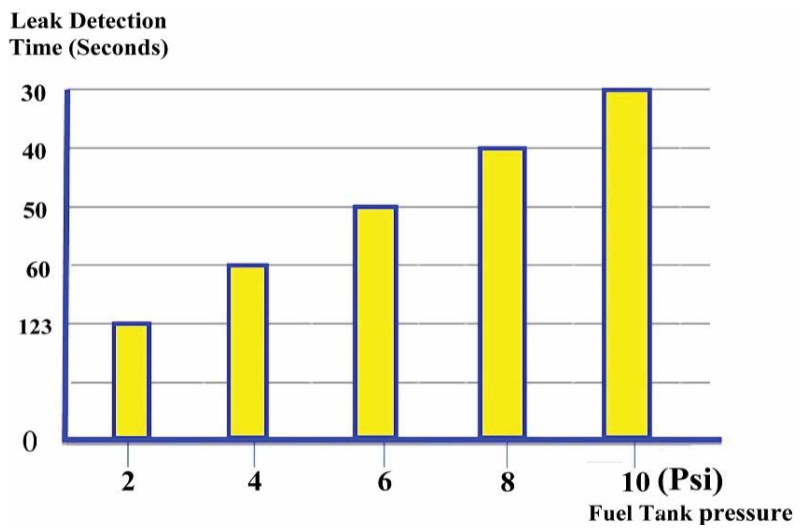

Figure 11: Leak detection time as a function of ullage pressure.

\section{Conclusion}

- Fuel tank leak on large transport airplanes is obviously a very serious concern. Fuel may leak onto hot brakes or hot surfaces and ignite. Even if the fuel leakage does not present ignition possibilities, it will nevertheless lead to a reduction in the aircraft range and possible emergency landing prior to destination arrival.

- Currently, there is no on-board system that can accurately detect a fuel leak and maintenance procedures are often hazardous, time consuming and staff intensive. Therefore, the 
Citation: Behbahani-Pour MJ, Radice G (2016) Fuel Leak Detection on Large Transport Airplanes. J Aeronaut Aerospace Eng 5: 174. doi: 10.4172/2168-9792.1000174

Page 10 of 10

authors have proposed a system, which can quickly detect any fuel tank leak before the aircraft departure, which requires low manpower and does not necessitate empty fuel tanks.

- The underlying hypothesis is that if a vessel is $100 \%$ leak proof, then when it is pressurized there should be no pressure drop. Any leakage will allow air to escape from the vessel, leading to the pressure inside the vessel to drop. The purpose of the experiments carried out was to prove that this hypothesis can be used to detect a fuel leak by measuring the pressure drop in tank ullage area. The sample fuel tank was therefore pressurized with nitrogen at different values, and fuel leak at different flow rates was introduced. Pressure changes in the ullage area of the tank were then recorded. The results of the experiment show that larger fuel leaks are detected more quickly and that higher pressures in the ullage area lead to a quicker determination of any fuel leak. In the experiment, a basic bourdon tube pressure gauge was used to detect the changes in the ullage pressure but we believe that more sensitive pressure measuring devices could detect very small fuel leak, of the order of just a few drops per minute.

\section{References}

1. JTSB (2009) Aircraft accident investigation report. China airlines B18616 Rept AA2009-7, Tokyo.

2. Langton R, Clark C, Hewitt M, Richards L (2009) Aircraft fuel systems John Wiley \& Sons Ltd UK.

3. Sheridan NG (2015) Fuel tank technology AGARD Rept. 771. Research group for aerospace research and development, France.

4. Airbus (2001) A340 Aircraft maintenance manual. Airbus manufacturer technical publications department, France 28: 13-14.
5. Maclsaac B, Langton R (2011) Gas turbine propulsion systems. Wiley Publication, USA.

6. Leak L (2014) Airman spots jet liner fuel leak. We never would have made into Japan.

7. Moir I, Allan S (2015) Aircraft systems: Mechanical, electrical and avionics subsystems integration (3rdedn). Wiley Publications, UK.

8. Transportation Safety Board of Canada (2014) Maintenance error- in-flight fuel leak air canada airbus A330-300 C-GHKX Vancouver International Airport British Columbia. Government of Canada.

9. Accident Investigation Final Report (2014) All engines-out landing due to fue exhaustion air transat airbus A330-243 marks C-GITS Lajes, Azones, Purtugal, Rept. 2/2007. Aviation Accidents Prevention and Investigation Department Portugal.

10. Barbara C (2009) A week of drama. Flight Global, UK.

11. FAA (2015) Accident overview history of flight. US Department of transportation, Washington.

12. Air Accidents Investigation Branch (2007) Report on the serious incident to Boeing 777-236, G-YMME on departure from London Heathrow airport on 10 June 2004. Department of Transport, UK.

13. Saive $H$ (2008) Boeing 787 spills fuel on runway as passengers alert crew.

14. Hoyle C (2007) UK Nimrods face new safety review following crash report. Flight Global, UK.

15. Airbus A320 (2015) A320 flight crew operating manual. Airbus Support Division Technical Publications Department, France, Vol. 3, 2015, pp.8-9.

16. Airbus A319/A320 (2010) Aircraft trouble shooting manual. Airbus Support Division Technical Publications Department, France 28: 219-220.

17. Wastnage J (2006) RAF sources leak September fatal Afghan Nimrod investigation findings, showing fractured fuel pipes. Flight Global, UK.

18. Wanger M, Norris G (2009) Boeing 787 Dreamliner. Zenith Press, USA
Citation: Behbahani-Pour MJ, Radice G (2016) Fuel Leak Detection on Large Transport Airplanes. J Aeronaut Aerospace Eng 5: 174. doi: 10.4172/2168 9792.1000174
OMICS International: Open Aceess Publication Benefits \&

\section{Features}

Unique features:

- Increased global visibility of articles through worldwide distribution and indexing

- Showcasing recent research output in a timely and updated manner

Special issues on the current trends of scientific research

Special features:

- 700+ Open Access Journals

$50,000+$ editorial team

Quality and quick editorial, review and publication processing

Indexing at major indexing services

Sharing Option: Social Networking Enabled

Authors, Reviewers and Editors rewarded with online Scientific Credits

Better discount for your subsequent articles

Submit your manuscript at: www.omicsonline.org/submission 